\title{
Editorial Dossier. Estudios Críticos Animales
}

\section{Editorial Dossier. Critical Animal Studies}

Alexandra Ximena Carolina Navarro: aleximca@gmail.com https://orcid.org/0000-0002-3429-249X

Instituto de Estudios Comunicacionales en Medios, Cultura y Poder Aníbal Ford; Facultad de Periodismo y Comunicación Social; Universidad Nacional de La Plata/ Instituto Latinoamericano de Estudios Críticos Animales (Argentina)

"Pensar esta guerra [contra los animales] en la que estamos inmersos no es solamente un deber, una responsabilidad, una obligación; es también una necesidad, una constricción a la cual, por las buenas o por las malas, directa o indirectamente, nadie podría sustraerse, y hoy menos que nunca. $Y$ digo «pensar» esta guerra porque creo que se trata en ella de lo que llamamos «pensar». El animal nos mira, nos concierne y nosotros estamos desnudos ante él. y pensar comienza quizás ahí." Derrida, J. (2008). El animal que luego estoy si(gui)endo. Madrid: Trotta, p. 45 
Proponemos este Dossier porque la cuestión animal es un emergente que nos concierne. Aun a aquellos que lo sienten ajeno, lejano e, incluso, burdo. La convivencia con otras especies y lo que nace fruto de ella nos atraviesa como humanidad, en todo el sentido que alcanza esta palabra.

Estamos viviendo en un contexto donde la Sexta Extinción no es una narración de ficción sobre el fin del mundo, sino un dato real que se acerca a pasos agigantados mientras lo ignoramos y continuamos con nuestras prácticas cotidianas de violencia naturalizada e institucionalizada contra los demás animales. En este marco, y en línea con el planteo de Derrida que abre esta presentación, como comunicadores estamos obligados a conocer del tema, de empaparnos de él y tomar la responsabilidad que ello nos implica al momento de hablar sobre él y darlo a conocer. En un contexto donde muchas veces este tema es banalizado, lo mínimo que podemos ofrecer es saber de qué estamos hablando cuando lo presentamos ante los demás, cuando opinamos sobre él. Luego, desde el lugar que nos convoque, desde donde la especificidad de la comunicación nos involucre, es importante que nos atraviese la idea de que lo animal es parte inherente de nosotros y que nuestra vinculación con ellos hace realmente la diferencia no sólo con ellos, sino con nosotros mismos, con los demás y con el planeta.

Esto sí, claramente es ideológico. Porque la cuestión animal, o poner lo animal en cuestión, es un posicionamiento político. Es lo que nos permite acercarnos a la real idea de que todas y todos somos animales, y que el poder razonar (o creer que somos la única especie que puede hacerlo) no podrá ser nunca razón para apropiarnos, despojar, esclavizar, utilizar y matar a nuestro antojo. Todas prácticas que, además de dañar y matar a los demás animales, están deteriorando al planeta al punto de poner nuestra propia supervivencia como especie humana en un punto de quiebre.

Con este objetivo, creímos oportuno invitar a investigadoras e investigadores reconocidos en sus respectivos campos de saber, que están trabajando el tema desde diversos puntos de Latinoamérica. Y, de esta manera, presentar, desde diversas aristas, qué es lo que se está planteando, discutiendo, revisando y reconstruyendo en torno a los animales no humanos.

Decidimos abrir el dossier con el artículo "Notas sobre religión, especismo y personalidad legal" de Pablo Suárez y Gonzalo Perez Pejcic. En este trabajo los autores buscan hacer evidente la vinculación que existe -aunque en general pasa desapercibida- entre algunas de las ideas centrales de las religiones judeo-cristianas (principalmente la construcción de la idea de hombre y de sujeto a partir de haber considerado a otros seres vivos como cosas y propiedades) y el humanismo antropocéntrico. El texto sugiere que esta genealogía, que alcanza a personas religiosas y laicas por igual, fue el primer puntapié a considerar que 
naturaleza-mujer-animal eran "cosas" al servicio del varón y que, por ello, se naturalizaron apropiables y utilizables. Esta concepción, que a su turno dio lugar a la afirmación de una excepcionalidad-superioridad del ser humano, incidió decisivamente en la concepción y atribución de personalidad jurídica que adopta el Derecho. A partir de dicho diagnóstico, los autores realizan un esbozo de reconstrucción de la noción de personalidad desde una mirada antiespecista.

Centrándonos en los discursos que nos atraviesan como argentinos y que nos influyen en nuestras decisiones alimentarias, sigue el artículo de Diego Forte "La construcción del Discurso Identitario Nacional Argentino: La historia de la carne". En él, adoptando como marco el Análisis Crítico del Discurso (ACD), se aborda la construcción del discurso especista que construye a la vaca como emblema nacional argentino. Partiendo desde la perspectiva teórica de Lakoff (2010), el artículo analiza tanto textos fundacionales como imágenes de diferentes períodos de la cultura argentina para dar cuenta de la importancia asignada al signo carne en la construcción de la Argentina moderna.

En esta línea, ligado a la cuestión del consumo de carne y lo que esto implica para el planeta, sigue el artículo "Sistema alimentario carnista y crisis climática: breve cartografía para comprender el problema", donde, en coautoría con María Marta Andreatta, realizamos una aproximación a la crisis climática actual y su relación con el sistema alimentario hegemónico argentino, de base carnista, integrando las miradas socio-cultural, nutricional y epidemiológica. El exhaustivo análisis de diversas publicaciones actualizadas sobre la temática permite concluir que las dietas estrictamente vegetarianas, habitualmente denominada veganas, constituyen una importante contribución para la mitigación de la crisis ambiental, a la vez que una alternativa saludable para los humanos y ética para los animales no humanos.

Finalmente, y cerrando esta primera sección sobre alimentación y cultura, el artículo de Fabio Oliveira "La dieta sexista: Contribuciones desde el ecofeminismo crítico para una decolonialización del paladar" propone una reflexión filosófica sobre las aproximaciones entre las variantes de la opresión, lo que resulta en que se naturalice la objetificación de los cuerpos de las mujeres y los animales no humanos por medio del control biopolítico y necropolítico, que animaliza a las mujeres y feminiza a los animales. Además, el artículo analiza que en un mundo globalizado, donde los intereses de los conglomerados agroindustriales -especialmente del sector agropecuario-, se expanden en perjuicio de la soberanía alimentaria, pensar la crítica ecofeminista al modelo de dieta alimentaria carnista elogiado y propagado por todo el mundo se vuelve fundamental para comprender las nuevas formas de colonización.

El artículo de Fabio es la bisagra perfecta para comprender el anclaje que existe entre la dieta carnista y la opresión sexista, y nos permite abrirnos a nuevas discusiones ligadas a los 
feminismos, los animalismos y la amistad entre especies. Es aquí que Anahí Gabriela González, en su artículo "Animales inapropiados/bles. Notas sobre las relaciones entre transfeminismos y antiespecismos" problematiza algunos presupuestos del feminismo antiespecista de corte radical de Carol Adams, sobre todo por su visión binaria del género y su postura respecto al trabajo sexual. Asimismo, la autora vincula el "especismo" con el cisheteropatriarcado ya que para ella "existe una escala jerárquica de valoración de las vidas que va de lo ideal hegemónicamente (el varón cisgénero heterosexual, blanco y adulto) al cuerpo del animal". De ahí que su conclusión sea la necesidad de establecer políticas veganas en clave transfeminista que apuesten por mundos más habitables para los cuerpos precarizados: mujeres cis y trans, varones trans, personas negras, enfermas, desviadas, y por supuesto, animales no humanos.

Por otro lado, el artículo "Memorias de un tiempo presente sobre el amor animal", escrito por Cassiana Lopes Stephan, recontextualiza el pensamiento ético-político respecto a las consideraciones contemporáneas sobre el amor, la amistad y el animalismo. La autora cuestiona el (no) lugar del animal en la tradición filosófica, basada en el principio de igualdad, y nos muestra hasta qué punto este precepto habría establecido una dinámica moralista que excluye y, de esta manera viola, a todos aquellos que transgreden los límites de la identidad humana. Para desarrollar su crítica del antropocentrismo que constituye la tradición filosófica basada en la sobrevaloración del hombre, Cassiana recurre a las interpretaciones de Michel Foucault sobre el autocuidado, las interpretaciones de Judith Butler sobre la violencia moral y el análisis de Jean-Pierre Vernant sobre el surgimiento de la filosofía en la antigüedad clásica. En este sentido, el ensayo de Cassiana se muestra como parte de la memoria de un amor que se nos había hecho imposible por la racionalidad de una moral humana.

En esta idea de revisar nuestras relaciones con los demás animales, siguen dos artículos: el primero, de Pablo Frasson, "Animales no humanos y suburbios de baja densidad", nos invita a repensar nuestras relaciones con ellos en el marco de las ciudades. El autor inicia con una pregunta: ¿Cómo convivimos entre diferentes, a partir del reconocimiento de la igualdad de derechos asociados a la dignidad básica humana y no humana? A partir de ahí, explica cómo las ciudades crecen y se expanden, y que esa expansión requiere consumo, que está íntimamente ligado al sufrimiento animal. Es con este puntapié inicial que se invita a reflexionar en torno a que modificar la forma de vivir en las ciudades puede contribuir a evitar ese sufrimiento y que, para ello, será necesario habitarla con una cosmovisión del mundo que valore la vida en todas sus formas, siendo conscientes de la existencia de otros seres con intereses diferentes.

Question, Vol. 1, N. ${ }^{\circ}$ 64, octubre-diciembre 2019. ISSN 1669-6581

Instituto de Investigaciones en Comunicación | Facultad de Periodismo y Comunicación Social | Universidad Nacional de La Plata La Plata | Buenos Aires | Argentina

Página 4 de 5 
El segundo artículo que cobra gran relevancia en este marco, es el de Laura Gutiérrez y su equipo, "Tendencia al reemplazo de animales de experimentación". Este trabajo señala que la aprobación para comercializar productos de uso humano se encuentra supeditada a la presentación de evidencia de su potencial toxicológico. En este sentido se realiza un recorrido histórico sobre el por qué fue necesario comenzar a ensayar productos en animales, cómo el avance científico lleva dejar de usarlos y, por último, cómo se fue implementando el reemplazo de animales a nivel mundial y la situación a nivel regional y local.

Finalmente, y para cerrar el dossier, el aporte de Alejandro Lambarry con su artículo "Los estudios animales en la literatura hispanoamericana contemporánea" nos permite conocer un esquema general de la aportación de la literatura hispanoamericana contemporánea en la discusión crítica de los estudios animales desde nuestra particularidad regional.

Esperamos haber podido brindar un breve panorama de las discusiones que están teniendo lugar en el Derecho, la Lingüística, la Comunicación, la Nutrición, la Bioética, la Filosofía, la Arquitectura, la Biología, la Literatura... y que estas lecturas estimulen otras indagaciones, otras revisiones y otras críticas.

Bienvenidos a la lectura. 